\title{
Functional subsets of lymphocytes
}

\author{
P. C. L. BEVERLEY
}

From the Imperial Cancer Research Fund Human Tumour Immunology Group, University College

Hospital Medical School, London

In this review I shall survey various properties of lymphocytes which allow clear distinctions to be drawn between different lymphocyte subsets. I shall discuss only thymus-derived (T) lymphocytes since these cells appear to play a key role in regulating the activities of other lymphoid cells (B cells and macrophages) as well as carrying out effector functions themselves. In the first section I shall discuss murine $T$ lymphocytes since most of the most decisive experimental studies have been carried out in this species, while the concluding section of the review will deal with human $\mathrm{T}$ lymphocyte heterogeneity.

\section{T Lymphocyte heterogeneity in the mouse}

The most useful tool for separation of $\mathrm{T}$ cells into different subsets has been the use of antisera to cell surface differentiation markers. Cells bearing a particular antigen may be killed by antiserum and complement or they may be detected and separated by such techniques as indirect immunofluorescence. Although $\mathrm{T}$ lymphocyte differentiation antigens may be detected by both heteroantisera and alloantisera (reviewed by Beverley, 1977) the most useful markers have been those detected by alloantisera. Table 1 lists some of the markers that have been particularly useful in elucidating the pathway of $\mathrm{T}$ cell differentiation in the mouse.

Table 1 Murine T lymphocyte surface antigens

\begin{tabular}{lll}
\hline Antigen & Linkage group & Reference \\
\hline H-2 & IX & Boyse and Old, 1968 \\
Ia & IX & Frelinger et al., 1974 \\
TL & IX & Boyse and Old, 1969 \\
Thy-1 & II & Raff and Wortis, 1970 \\
Ly-1 & XII & Boyse et al., 1968 \\
Ly-2 & XI & Boyse et al., 1968 \\
Ly-3 & XI & Boyse et al., 1971 \\
Ala-1 & $?$ & Feeney and Hammerling, 1976 \\
\hline
\end{tabular}

Using a panel of antisera allows the construction of a scheme for $\mathrm{T}$ cell differentiation such as that given in Fig. 1. This is a considerable over-simplification since many other $\mathrm{T}$ cell markers have been

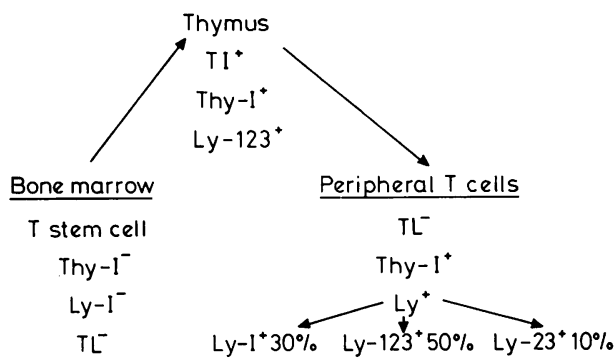

Fig. 1 Differentiation of $T$ cells.

described (Beverley, 1977; Simpson and Beverley, 1977). However, it illustrates the important point that during differentiation of $\mathrm{T}$ cells from stem cells resident in the bone-marrow to mature peripheral $\mathrm{T}$ cells there is a major reorganisation of the cell surface. Some markers (for example, T1) are lost while others appear (for example, Ala-1 which is present only on mature effector cells of both $T$ and $B$ lineages). In the peripheral lymphoid tissues the Ly-1, 2, and 3 markers allow a division of the $\mathrm{T}$ cells into three major subsets with different surface expression of the three antigens (phenotype) and distinct functional properties (Fig. 1).

Although the realisation that different subsets of lymphocytes served different functions-for example, that $B$ cells produce antibody and $T$ cells mediate delayed hypersensitivity - preceded the use of antisera to differentiation antigens, use of these reagents has allowed an analysis of $\mathrm{T}$ cell function which was previously impossible. Particularly enlightening are the studies by Cantor and Boyse (1975a, b) of mixed lymphocyte culture (MLC) responses. Their findings may be summarised as follows.

(1) The major portion of the proliferative response in MLC is due to $\mathrm{Ly}-\mathrm{1}^{+}$cells.

(2) The $\mathrm{Ly}-\mathrm{1}^{+}$cells respond to alloantigens coded in the I region of the major histocompatibility complex (MHC).

(3) Cytotoxic effector cells generated in MLC and their precursors are $\mathrm{Ly}-23^{+}$. 


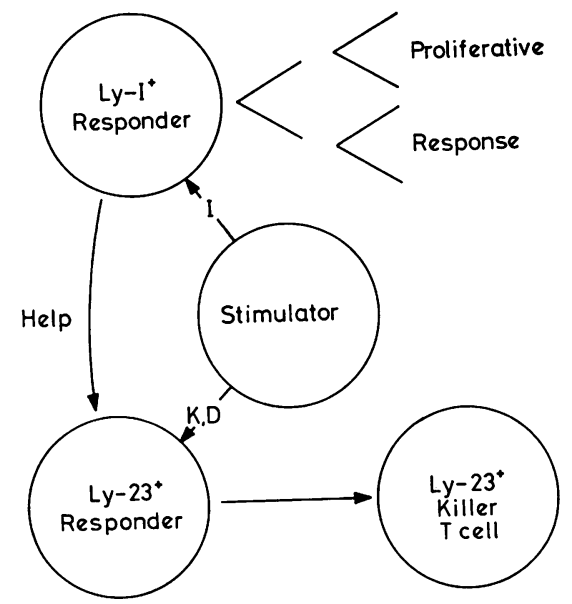

Fig. 2 The mixed lymphocyte culture (MLC) responses.

(4) The target antigens of the cytotoxic cells are $\mathrm{H}-2 \mathrm{~K}$ and $\mathrm{D}$.

(5) Generation of an optimal cytotoxic response requires the presence of $\mathrm{Ly}-1^{+}$cells.

These important findings are summarised diagrammatically in Fig. 2. The study established not only that different cells mediate different functions but also that the different cells respond to antigens coded in different regions of the MHC. In addition the importance of cell-cell interactions in generation of effector cells was emphasised.

Now it could be argued that the MLC is a nonphysiological in-vitro culture artefact, and one might ask what relevance MHC recognition has to host defence against bacteria and viruses? The now classical experiments of Zinkernagel and Doherty (reviewed in Doherty et al., 1976) provide an answer. They show that cytotoxic $\mathrm{T}$ cells, immune to viral antigens, recognise not just the viral antigens but viral antigens in association with self MHC antigens. The relevant MHC antigens are coded in the $\mathrm{K}$ and $D$ regions. In addition it has now been shown that anti-viral cytotoxic cells are $\mathrm{Ly}-\mathrm{23}^{+}$(Pang et al., 1976).

Does this self + antigen recognition apply only to $\mathrm{Ly}-23^{+}$killer cells? Somewhat more indirect evidence than that for killer cells shows that helper cells for antibody production recognise soluble protein antigens in association with I region coded antigens (Erb et al., 1976). The helper cells have also been shown to have the Ly-1+ phenotype (Feldmann et al., 1975). In other experiments it has also been demonstrated that the Ly-1+ cells which mediate delayed type hypersensitivity reactions are also I region restricted (Miller et al., 1976).

Taken together these data suggest that all $T$

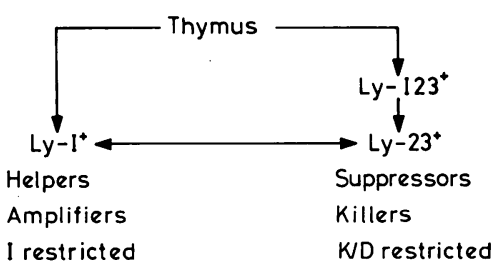

Fig. 3 T cell differentiation.

lymphocytes recognise extrinsic antigen in associa-ñ tion with self MHC antigens and, furthermore, that there are two major subtypes of T cells (Fig. 3). The. Ly-1+ cells are helper/amplifiers for other cell types $\overrightarrow{-}$ and respond to $I$ region antigens, while $L y-(1) 23+\omega$ cells are suppressor/killers and $K / D$ responsive. In addition, Fig. 3 emphasises the interactions betweenis these two broad categories of $\mathrm{T}$ cell.

\section{Human lymphocyte subsets}

In this section I briefly review our present under-윽 standing of human lymphocyte heterogeneity. Fig. 4summarises the distribution of cell phenotypes thato may be found in human peripheral blood as distinguished by a number of widely used markers These separation techniques have allowed consider- able advances in understanding of human cellugar immune responses but do not allow adequage definition of the non-T (non-E-rosetting) subsets nero subfractionation of the $T$ cells.

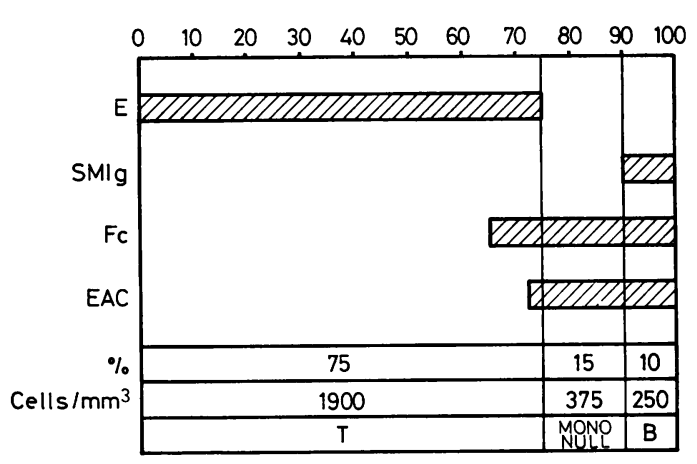

Fig. 4 Normal lymphocyte phenotypes.

Three sets of markers have allowed a start o1 investigations of human $T$ cell subsets. The first is 0 the use of IgM and IgG rosetting. Two subpopulations of $T$ cells can be identified by the use of ox redo blood cells coated with IgM or IgG antibody. The T.M cells comprise about $55-60 \%$ and the T. $\mathrm{G}$ cells $10 \%$ of peripheral blood $\mathrm{T}$ cells (Moretta et al., $?$ 1976). Complete functional studies of these subsets 0 have not so far been reported but they showo 


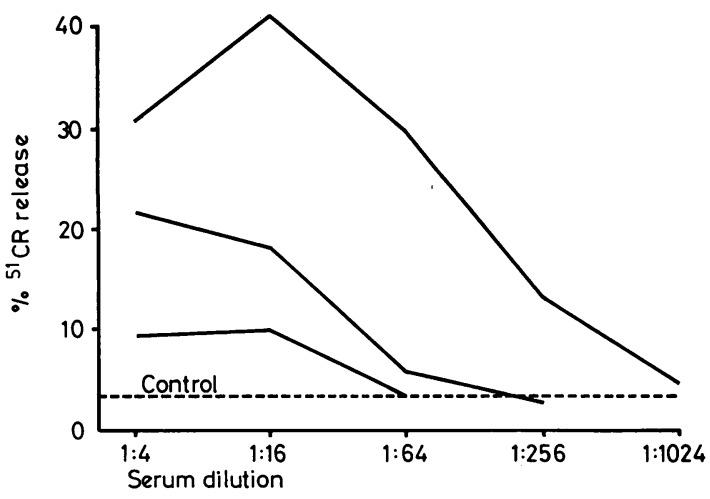

Fig. 5 Cytotoxicity of juvenile rheumatoid arthritis $(J R A)$ sera. Three JRA sera were assayed on nylon column purified human PBL $(>90 \% E+)$ using a two-stage ${ }^{51} \mathrm{Cr}$ release assay with absorbed rabbit serum as a source of complement.

differences in response to PHA. More importantly, it has also been demonstrated that the $\mathrm{T}$ cells required to potentiate a $B$ cell response to pokeweed mitogen reside in the T. $M$ subset. T. $G$ cells, on the other hand, inhibit this response (Moretta et al., 1976).

There are more complete data on the use of two different types of antisera to distinguish $\mathrm{T}$ cell subsets. Schlossman and his colleagues have investigated the properties of sera from patients suffering from juvenile rheumatoid arthritis (JRA). Active sera have an autoantitody capable of killing up to $40 \%$ of human peripheral blood T cells (Strelkauskas et al., 1978). In our experience the sera are rather more heterogeneous (Fig. 5) giving variable levels of plateau killing of peripheral blood $\mathrm{T}$ lymphocytes. Nevertheless, in Schlossman's hands several high killing sera have given repeatable results in studies of lymphocyte function (Strelkauskas et al., 1978; Schlossman et al., 1978).

An alternative approach is to develop specific heteroantisera. Rabbit antisera to $T$ lymphocytes may be absorbed with autologous B lymphocytes (Evans et al., 1977), or T leukaemia cells (Evans et al., 1978) to derive sera recognising subsets of $T$ lymphocytes. In this way two markers TH1 and TH2 have been identified. Table 2 summarises (and simplifies) the data derived from studies with JRA sera and anti TH1 and TH2 sera. It appears that most of the functions measured can be ascribed to two major subsets of lymphocytes-the $\mathrm{TH}^{+}$ helper/amplifier, which appears broadly equivalent to the mouse $\mathrm{Ly}-1^{+}$cell, and the $\mathrm{TH}^{+}{ }^{+} \mathrm{JRA}^{+}$suppressor/killer, broadly equivalent to the mouse Ly- $23^{+}$. It is interesting that the cells which give an in-vitro proliferative response to soluble antigen do
Table 2 Summary of data derived from studies with juvenile rheumatoid arthritis (JRA) sera and anti-THI and TH2 sera

\begin{tabular}{llll}
\hline \multicolumn{3}{c}{ Antigens } & \\
\hline Function/response & TH1 & TH2 & JRA $^{+}$ \\
MLC & + & - & - \\
HELP & + & - & - \\
CML & ND & + & ND \\
Suppression & - & + & + \\
Soluble antigen & - & - & + \\
\hline
\end{tabular}

not fall clearly into either category. Similarly in the mouse it is unclear which subset of $T$ cells is most important in this response. In summary, it appears that distinctions, both functional and phenotypic, between the major lymphocyte subsets have been conserved during mammalian evolution.

Since it is now clear that major subsets of human lymphocytes having distinct surface and functional properties can be defined, we might ask the relevance of these to the pathogenesis of disease. As yet data are scanty, but there is already evidence for disturbances in numbers of T. $M$ and T. g cells in certain immunodeficiency and autoimmune disorders (Moretta et al., 1977) and in multiple sclerosis (Santoli et al., 1978). Preliminary evidence also suggests that JRA patients with detectable autoantibody lack circulating suppressor cells (Schlossman et al., 1978).

Rapid progress may be expected in this area when the existing markers are improved. Present heterosera suffer from limited availability, difficulty in reproducing successful immunisations, and multiple specificities present in the same serum. JRA sera are not readily available and only untreated patients have usable titres. Furthermore, the number of cells killed may vary (Fig. 5), suggesting multiple specificities within the sera. Perhaps the most promising avenue for advance is the use of somatic cell hybridisation to produce monoclonal antisera (Kohler and Milstein, 1976). Already an antigen present on human thymocytes but not peripheral $T$ cells has been defined (McMichael et al., 1978) which is perhaps equivalent to the mouse TL antigen. It is to be expected that peripheral $\mathrm{T}$ and $\mathrm{B}$ cell markers will shortly be described.

\section{References}

Beverley, P. C. L. (1977). Lymphocyte heterogeneity. In $B$ and $T$ Cells in Immune Recognition, edited by $F$. Loor and G. E. Roelants, pp. 35-57. Wiley, London.

Boyse, E. A., Itakura, K., Stockert, E., Iritani, C. A., and Miura, M. (1971). Ly-C: a third locus specifying alloantigens expressed only on thymocytes and lymphocytes. Transplantation, 11, 351-353. 
Boyse, E. A., Miyazawa, M., Aoki, T., and Old, L. J. (1968). Ly-A and Ly-B: two systems of lymphocyte isoantigens in the mouse. Proceedings of The Royal Society Series B, 170, 175-193.

Boyse, E. A., and Old, L. J. (1969). Some aspects of normal and abnormal cell surface genetics. Annual Review of Genetics, 3, 269-290.

Cantor, H., and Boyse, E. A. (1975a). Functional subclasses of $T$ lymphocytes bearing different Ly antigens. 1. The generation of functionally distinct $T$ cell subclasses is a differentiative process independent of antigen. Journal of Experimental Medicine, 141, 1376-1389.

Cantor, H., and Boyse, E. A. (1975b). Functional subclasses of $\mathrm{T}$ lymphocytes bearing different Ly antigens. II. Co-operation between subclasses of Ly cells in the generation of killer activity. Journal of Experimental Medicine, 141, 1390-1405.

Doherty, P. C., Blanden, R. V., and Zinkernagel, R. M. (1976). Specificity of virus-immune effector $T$ cells for H-2K or H-2D compatible interactions: implications for H-antigen diversity. Transplantation Reviews, 29, 89-124.

Erb, P., Feldmann, M., and Hogg, N. M. (1976). Role of macrophages in the generation of $\mathrm{T}$ helper cells. IV Nature of genetically related factor derived from macrophages incubated with soluble antigens. European Journal of Immunology, 6, 365-372.

Evans, R. L., Beard, J. M., Lazarus, H., Schlossman, S. F., and Chess, L. (1977). Detection, isolation, and functional characterization of two human T-cell subclasses bearing unique differentiation antigens. Journal of Experimental Medicine, 135, 221-233.

Evans, R. L., Lazarus, H., Penta, A. C., and Schlossman, S. F. (1978). Two functionally distinct subpopulations of human $\mathrm{T}$ cells that collaborate in the generation of cytotoxic cells responsible for cell-mediated lympholysis. Journal of Immunology, 120, 1423-1428.

Feeney, A. J., and Hammerling, U. (1976). Differentiation of murine $T$ and $B$ lymphocytes from resting to effector cells, as characterised by ALA-1 (activated lymphocyte antigen-1). In Proceedings of the Second International Congress on Cell Differentiation. North Holland Publishing, Amsterdam.

Feldmann, M., Beverley, P. C. L., Dunkley, M., and Kontiainen, S. (1975). Different Ly antigen phenotypes of in-vitro induced helper and suppressor cells. Nature (London), 258, 614-616.

Frelinger, J. A., Niederhuber, J. E., David, C. S., and Schreffler, D. C. (1974). Evidence for the expression of Ia (H-2 associated) antigens on thymus derived lymphocytes. Journal of Experimental Medicine, 140, 1273-1284.
Köhler, G., and Milstein, C. (1976). Derivation o $\overline{\overline{\mathrm{P}}}$ specific antibody-producing tissue culture and tumo lines by cell fusion. European Journal of Immunology, 6. 511-519.

McMichael, A. J., Pilch, J. R., Galfré, G., Mason, D. Y. Fabre, J. W., and Milstein, C. (1979). A human? thymocyte antigen defined by a hybrid myelom monoclonal antibody. European Journal of Immunology 9, 205-210.

Miller, J. F. A. P., Vadas, M. A., Whitelaw, A., and Gamble, J. (1976). Role of major histocompatibility complex gene products in delayed type hypersensitivity? Proceedings of the National Academy of Sciences, $73 \vec{\circ}$ 2486-2490.

Moretta, L., Ferrarini, M., Mingari, M. C., Moretta, A. $\vec{\omega}$ and Webb, S. R. (1976). Subpopulations of human To cells identified by receptors for immunoglobulins an mitogen responsiveness. Journal of Immunology, 117 2171-2174.

Moretta, L., Mingari, M. C., Webb, S. R., Pearl, E. R., $\vec{\omega}$ Lydyard, P. M., Grossi, C. E., Lawton, A. R., and Cooper, M. D. (1977). Imbalances in T cell sub-r populations associated with immunodeficiency ando autoimmune syndromes. European Journal of $\mathrm{Im}_{-}=$ munology, 7, 595-700.

Moretta, L., Webb, S. R., Grossi, C. E., Lydyard, P. M., and Cooper, M. D. (1977). Functional analysis of two human T-cell subpopulations. Help and suppression of B-cell responses by $T$ cells bearing receptors for IgMor IgG. Journal of Experimental Medicine, 146, 184-200.

Pang, T., McKenzie, I. F. C., and Blanden, R. V. (1978). Co-operation between mouse $T$-cell subpopulations in the cell-mediated response to a natural poxvif pathogen. Cellular Immunology, 26, 153-159.

Raff, M. C., and Wortis, H. H. (1970). Thymusa dependence of $\theta$-bearing cells in the peripheral lymphoid tissues of mice. Immunology, 18, 931-943.

Santoli, D., Moretta, L., Lisak, R., Gilden, D., and $\overrightarrow{0}$ Koprowski, H. (1978). Imbalances in $T$ cell sub- 3 populations in multiple sclerosis patients. Journal of Immunology. 120, 1369-1371.

Schlossman, S. F., Evans, R. L., and Strelkauskas, A. J (1978). Human T-cell subsets with regulatory functions. In Inserm Symposium 8, edited by B. Serrou and C. Rosenfeld, North-Holland, Amsterdam.

Simpson, E., and Beverley, P. C. L. (1977). T cello subpopulations. Progress in Immunology, 3, 206-216.

Strelkauskas, A. J., Schauf, V., Wilson, B. S., Chess, L. and Schlossman, S. F. (1978). Isolation and character-ization of naturally occurring subclasses of human peripheral blood $\mathbf{T}$ cells with regulatory functions. Journal of Immunology, 120, 1278-1282. 